\title{
An Exploration for Cultivation of Internationalized Capabilities at NPU
}

\author{
Huaxing Li \\ Office of International Cooperation \\ Northwestern Polytechnical University \\ Xi'an, China \\ hxli@nwpu.edu.cn \\ Wentao Zhang \\ Office of International Cooperation \\ Northwestern Polytechnical University \\ Xi'an, China \\ zhangwentao@nwpu.edu.cn
}

\author{
Jun Zhang \\ Northwestern Polytechnical University \\ Xi'an, China \\ zhangjun@nwpu.edu.cn \\ Wubin Sun \\ Office of International Cooperation \\ Northwestern Polytechnical University \\ Xi’an, China \\ wubinsun@nwpu.edu.cn
}

\begin{abstract}
In order to respond to the requirement of Ministry of Education (MOE) - cultivating a large scale of talents who are equipped with international view, have good understanding of international rules and are able to participate in international affairs and competitions, Northwestern Polytechnical University (NPU) started to explore education reform of internationalized talents cultivation and established the pilot project as one of the MOE's education reform projects. Through theoretical study and practical execution, the administrative departments and the schools of the university coordinated with each other developed an internationalized education pattern featured with a short term 'One E four Ts', which means Chinese students and international students will have classes Together, take exams Together, do research Together, and have social activities Together under the same suitable and integrated Environment at campus. Moreover, the continuity study from bachelor through master to $\mathrm{PhD}$ level is realized. A corresponding teaching system to ensure the realization of the 'One $E$ four Ts' education pattern in which full English taught disciplinarians and majors are established. And with this new teaching system, NPU is making continuous efforts in exploring and creating internationalized talent cultivation patterns, pushing forward the internationalization of the university both in education and management, improving global reputation and internationalized education capability.
\end{abstract}

KeyWord $\longrightarrow$ national education system reform; internationalized education pattern; international class

\section{INTRODUCTION}

\section{A. Aim Changing of Personnel Training in China}

In a long period of time after 1949, higher education is aimed at training engineers and scientists in China. However, this objective has greatly changed after 1978. Because of the reform and opening-up policy coming into force, China had got a rapid development in international communication and cooperation as well as all-round participation in the global society, not only in science and technology but also in culture and economy, especially after entering the 21st century. The changing of the objective is fully presented by the scale and regulations of talent cultivation written in the plan, which is China MOE's(Ministry of Education) National Medium-term and Long-term Education Reform and Development Plan (2010-2010). The plan also pointed out that China needs to enhance international communication and cooperation, make use of the opening-up policy in order to boost reform and development, explore multilevel, multi-field communication and cooperation in education to promote internationalization of China's education. We can also draw lessons from advanced education theory and experience to promote the development of education reform in China, and to improve our international status, influence and competence. In order to be consistent with the development of national economy, a large scale of talents who are equipped with international view, have good understanding of international rules and are able to participate in international affairs and competitions, is badly in need of. Ease of Use

\section{B. Aim Changing of Personnel Training in NPU}

The Ministry of Industry and Information Technology of China, which Northwestern Polytechnical University (NPU) is affiliated with, has put forward more detailed requirements of training aim and mode of higher engineering education, namely, education and teaching reform needs to be deepened; students' innovative and experimental ability needs to be improved. Education should be in consistent with the requirement of the opening-up of nation's economy and the pace of "going global" strategy. So univerisities should take measures to train more students to be equipped with global view, advanced knowledge, innovative and international competing abilities, to be familiar with international rules and able to communicate across different cultures, to carry out international communication and cooperation.

\section{The Exploration of Internationalized Cultivation Pattern}

Under such background, NPU is exploring a pattern to promote the internationalization development, and how to make use of it to accelerate the cultivation of internationalized talents. 
To explore the internationalized education mode, especially in Aeronautical Engineering, NPU successfully applied the national education reform pilot project- "exploration of internationalized education mode reform project" from the Ministry of Education of China. On October 8th 2011, the first international class in NPU started its teaching activity. It was the first time in NPU that Chinese students and international students taking the same courses, moreover, the courses were taught in English-a milestone in the development of internationalized education in NPU.

\section{RESEARCH AND PRACTICE}

Through the establishment of the international class, it is clear to see the features of NPU's internationalized education mode:

\section{A. Originating of the Idea}

After the practice of the pilot project, the university has defined the core idea of internationalized personnel training"One E, Four Ts", which means under the same education environment, Chinese students and international students will have classes together, take exams together, do research together, and participate activities together. Following this idea, the university also set up an education system that English teaching can cover all the degree courses from undergraduate to doctorial disciplines. After an all-round research and scientific analysis, NPU has carried out the comprehensive construction of the internationalized environment from policy-making and other necessary aspects. The "four-together" mode and the "one environment" construction are interrelated and will gradually become the foundation of the reform work of this pilot project

\section{B. A new Path for International Study}

After four years practice, NPU is exploring a special way of personnel training, which is "study abroad without going abroad”. In China, most universities will have a separated class for international students, or give lectures to Chinese students with two languages. Some universities will send students abroad to study for one or two years-the " $2+2$ " or " $3+1$ "project. However, the pilot project in NPU is different. The international class will not have extra pressure while the students can enjoy the high quality international education resources. The "four-together" mode has shown a 3A effectAccessibility, Affordability and Advancibility.

\section{Theoretical Research and Practice}

With a sufficient preparation, the international class project got the permission of MOE. After the coordination with administration departments, NPU chose three predominant ones-Flight Vehicle Design and Engineering, Electronic Science and Technology and Electrical Engineering and Automation, of the predominant schools-School of Aeronautics, School of Electronics and Information, and School of Automation respectively as the pilot schools and majors. The four predominant disciplines chosen as the pilot graduate programs are Aerospace Science and Technology, Information and Communication Engineering, Electrical Engineering and Control Science and Engineering.
In 2012, Mechanical Engineering in School of Mechanical Engineering was added to the pilot project. Now, the university has set up the English teaching system in these four schools, covered four undergraduate majors and five graduate disciplines. As for the international class, 126 undergraduate courses, 92 graduate courses are all taught in English, moreover, the course outline, content and teaching calendar are all available. By means of purchasing, editing, translating and publishing, the university has accumulated a series of high quality English textbooks.

\section{Paying Equal Attention to Teaching and Learning, Finding out New Methods to Conform to The Internationalized Education Rules}

Based on the current situation, the university encourages teachers to learn from other universities their advanced experience, analyze newly appeared problems and try different ways to solve them. For example, 9 mathematic courses are facing the problem of lacking of teachers, inadequate English teaching ability, old-fashioned examination mode and students' lacking of enthusiasm. To solve those problems, NPU has given support not only in policy making but also in finance to encourage teachers try something new. Students of international class come from different countries have different culture background, different way of thinking and study, in allusion to this situation, the university encourages teachers to explore more teaching methods to attract students' diversified interest. Now, math course was taught through group discussion, student one-to-one study, lecturer and teaching assistant perform his own functions etc., these teaching methods are well accepted by the students of international class.

\section{E. Exploring Suitable Management Mechanism to Pushing Forward the Education Reforme Project}

A scientific, effective, transparent and negotiable management mode to guarantee the pilot project's processing systematical and standardized. The pilot project is a brand new start in NPU, therefore, little experience can be found in the former teaching and learning activities. The university has set up the office of internationalized education reform pilot project, the president of the university is the head of the office. Through the last two years, the related responsible person met every other week to discuss the reform work, coordinate between administration offices and have made more than 30 regulations to serve for the education reform, which ensured the smooth operation of the project.

\section{OFFER CROSS-CUltural COMMUNiCATION TO IMPROVE STUDENTS COMPREHENSIVE ABILITY}

\section{A. Create the Second Class to Practice Cross-Cultural Communication Ability}

In order to train student talents who are equipped with cross-cultural communication and international cooperation ability, NPU has been paying much attention to students' communication ability and comprehensive quality cultivation, In the last three years, the university has worked very hard to establish the second classroom-extra curriculums, tried our best to improve communication ability of student in the international class under the cross-cultural background, making it a positive supplement to the first classroom-course teaching. 
The school offered many activities in different fields which aimed to cultivate students' higher artistic attainment and better personality, and to meet the different needs of Chinese students as well as international students.

In 2012, in order to push forward the education reform work, NPU carried out a poll, to absorb suggestions from every aspect. The result showed that: after the pilot project started, Chinese higher education gained more recognition, internationalized teaching quality has largely improved, talents training ability is apparently better. Students from international class also feel good about the course content, communications with teachers and Chinese students, as well as other support offered by the university.

\section{B. Rich Variety of Activities Help Establish a More Internaitonalized Campus Culture}

One important element of the pilot project is to establish a internationalized campus culture among students. Every semester, the university will ask for suggestions from teachers and students and then play the role of top design to arrange international class activities that pay attention to students' participation. Activities including English speech contest, mini sport meeting, badminton contest, Culture Bridge and Crossculture Communication and Management lectures, as well as establishing the "Shinning Team" volunteer service. These activities offer more choice to students apart from daily study, more opportunities to communicate with each other, chances to enhance team work, and most important, create an internationalized campus culture.

NPU has been giving full support to the extra curriculums, encouraging students to discover the world apart from courses. There are many lectures held by the university, especially for international class, trying to inspire them to understand, accept and appreciate the core of culture, from the point of view of respect. There is also a special fund to support all the activities.

Students in international class organized the "Shinning Team” volunteer service team spontaneously. The team will take part in many charity activities in the society, through which they strengthened the service awareness. The students also start an English newspaper Bridge whose main content is to present different culture and customs of different countries. Planning, compiling and editing, all the jobs are done by students themselves.

In June 2012, the office of internationalized education reform pilot project received a Thank-you Letter. It said: ....as the students come from other parts of the world, we can acquire knowledge with Chinese students in the same classroom and we can learn Chinese. We have chance to take part in many campus activities such as English speech contest, English opera contest, football game and the Model United Nations. No matter where we are, we can feel caring from our teachers and classmates, they will give us help when it is needed. We are convinced that with the support of the university, we will be ready not only in academic but also our body, to finish our study with high quality, in our second home-China.

\section{Future Plan of The Cultivation of Cross-Cultural Communication Ability}

One of the advantages of Xi'an is that, there are all kinds of universities and education institutions. NPU will make full use of the education resources in Xi'an to introduce more qualified teachers in the field of humanities and arts, to provide more art and culture courses. For example, singing, dancing, painting, and Chinese folk art like calligraphy and Kongfu etc. In the future, NPU will no longer only be the place where students acquire knowledge, but also a training base for comprehensive quality of cross-cultural communication ability and international leadership.

\section{INTERNATIONALIZED EDUCATION MODE PUSH} FORWARD THE INTERNATIONALIZATION OF THE UNIVERSITY

After four years practice, the project give a major push to the internationalization of the university. The core idea of the international class is the "four together", which greatly eliminated the difference between training Chinese students and international students. The double-track system is also a strong impulse to the internationalization of university's management mechanism, strategic, teaching staff cultivation and teaching system.

\section{A. Break the Old Management Mechanism Which Was a Shackle of the Internationalization of the University}

The education system of "international class" is conflicted with the old system in NPU, therefore, when Chinese students and international students started to practice the "four together" system, the most obvious confliction is the management mechanism. In order to solve the problem, the university adopted the coordinating management-led by the working group leaders, administration departments and schools perform their own duties, meanwhile cooperated closely and effectively. The working group made out regulations and set policies to solve the problems that appeared in the processing of the project, successfully defused the conflicts between the new managing system and the old one.

\section{B. Push Forward the Internationalized Curriculum Construction}

In order to carry out the pilot project, NPU made efforts to established a corresponding English teaching system for the cultivation of internationalized talents, in which teaching outlines are specially formulated. To ensure the teaching quality, NPU not only introduced classical and the latest international text books but also international experts to give English lectures. With these efforts, a degeneration cycle of international class was broke: at first, Chinese professors will taught Chinese students in English with the original text books, later the teachers will taught English books in Chinese, while at last, they will use the translated books in the class. Since the international students and Chinese students are having classes together, and international professors do not understand Chinese, the degeneration problems was eliminated.

In the practice, a most important point of the pilot project is the innovation of the class. The course should not only focus on the theoretical study, but also the practical ability. When design the courses for the international class, NPU first drew lessons 
from the latest development of the corresponding disciplines in the world, then the university did an intensive study to the teaching mode and examination method reform, in order to offer courses that is more competitive and attractive to international students. For example the Mechanical Drawing course, in international class, the course adopted the same teaching methods as other countries_-cut down teaching hours and increase practicing hours.

\section{Establishe a Platform for the Cultivation of Internationalized Talents}

After a continuous efforts, the pilot project "exploration of internationalized education mode reform project" has increased its team-there are four schools have established the international class. This exploration project give a vigorous boost to the internationalized development of NPU. More schools are making out their plan to open international class, including School of Astronautics, School of Marine Technology, School of Material Science, School of Mechanics, Civil Engineering and Architecture, School of Power and Energy and School of Management. An integrated internationalized education platform is come into being.

The pilot project also push forward the establishment of internationalized teaching system in schools. More schools is adjusting the old teaching outline, making efforts to open more English-taught majors and course, which lays a solid foundation to international academic communication and credits transfer. It is also the first step to develop joint program with foreign universities. Not long before, there are some foreign universities wanted to establish cooperation relationships with NPU, but not succeeded because of lacking of the description of English-taught courses and English-taught majors. With the establishment of English-taught course system, international student exchange no longer has barriers.

Another outcome brought by the pilot project is the student international exchange. Stimulated by the project, more and more students are actively participating in international exchange programs: doctoral program, exchange program, summer camps and double degree program etc.. Taking the national supported student program as an example, in 2014, 132 NPU students were supported by China Scholarship Council (CSC) to study abroad, increased 35\% than 2013, the largest number among universities in Shaanxi. In it, 43 students are pursuing further study for doctor degree abroad.

Meanwhile, cooperation between foreign universities have reached a higher level. In March 31, 2014, president Xi Jinping visited Belgium and witnessed the signing ceremony of the Privileged Partnership Agreement and other four cooperation agreements between NPU and Vrije Universiteit Brussel
(VUB). After the signing ceremony, two universities immediately came into operation: $3+2$ undergraduate students exchange program, doctoral program, short term exchange program etc.. All these programs are going on very well now. Based on the fruitful cooperation between the two universities, in 2014 the vice president of VUB, in charge of international cooperation, was awarded by Chinese government " national friendship award. ”

\section{CONCLUSION}

The national education reform pilot project in NPU_-"The exploration of the internationalized education mode" has been taking into effect for four years. In the past few years, NPU has overcome many difficulties, meanwhile, got more experience. During the practice of the reform, NPU also discussed the problems and shared experiences with experts of education from all over the world. In June 2014, NPU presented the practice of the international class in the International Forum of Leading Aerospace Universities, held in Berlin, German. The innovative management mechanism and teaching system attracted lot interests from all the delegates and the paper was the only one from China which has been published.

The pilot project not only push forward the processing of internationalization of NPU, but also contributes to NPU's international reputation and influence. In the last few years, NPU has leveled up in the QS world university rankings, according to the feedbacks from QS, one of the reasons is the establishment of the English courses in the international class.

Even though, the "exploration of internationalized education mode reform project” has faced many difficulties since it started, after 4 years research and practice, NPU has learned a lot experience from the project which can be used into the cultivation of internationalized talents. From this point of view, this kind of exploration deserves more detailed study in the future, in order to better practice the higher education reform.

\section{REFERENCES}

[1] Ortega Y. Gasset. Mission of the University[M]. Zhejiang: Zhejiang Education Publishing House, 2001.12

[2] China Association of Higher Education. Internationalization of University: Theory and Practice[M]. Beijing: Peking University Press, 2007.11

[3] $\mathrm{Hu}$ Yiwu. Evaluation and Mechanism Research about Internationalization of Chinese Universities[M]. Guangzhou: South China University of Technology Press, 2009.12

[4] Huaxing Li, Jun Zhang, Wentao Zhang, Fei Xu. The Exploration of Internationalized Education Mode in Aeronautical Engineering at NPU. Aerospace University of the Future Papers. Berlin: International Forum of Leading Aerospace Universities, 2014:113-116 